\title{
Old unradiogenic Os in deep mantle metallic liquid from large gem IIa diamonds
}

\author{
Evan M. Smith ${ }^{1}$, Stephen H. Richardson ${ }^{2}$, Steven B. Shirey ${ }^{3}$ and Wuyi Wang ${ }^{1}$ \\ ${ }^{1}$ Gemological Institute of America, New York City, NY, USA \\ ${ }^{2}$ Department of Geological Sciences, University of Cape Town, Rondebosch 7700, South Africa \\ ${ }^{3}$ Department of Terrestrial Magnetism, Carnegie Institution for Science, Washington, DC USA
}

\section{Introduction}

Many of the world's largest and most valuable diamonds such as the Cullinan, Lesotho Promise, Constellation and Koh-i-Noor share an unusual set of physical characteristics, suggesting they form by a common mechanism. The most noted characteristic is their nitrogen-deficient character, classifying them as Type IIa. The paragenesis of such diamonds is enigmatic in that they have not been connected to the processes forming more common Type I diamonds or other varieties of Type II diamonds. Research on their geological origin has been scant as these Cullinan-like Type II diamonds are especially valuable as gemstones and rarely contain inclusions.

\section{Inclusion phases}

Recent findings have demonstrated a recurring set of inclusions in large, high-quality Type IIa diamonds, distinct from those of more familiar lithospheric/sublithospheric diamonds (Smith et al., 2016). The most abundant inclusion is a metallic, Fe-Ni-C-S multi-phase (cohenite + Fe-Ni alloy + pyrrhotite) assemblage with a surrounding fluid jacket of $\mathrm{H}_{2}$ and $\mathrm{CH}_{4}$. The second most abundant inclusion is former $\mathrm{CaSiO}_{3}$ perovskite, now retrogressed to lower-pressure minerals but also associated with metal, $\mathrm{H}_{2}$, and $\mathrm{CH}_{4}$. Trapping $\mathrm{CaSiO}_{3}$ perovskite inclusions constrains the minimum depth of formation to $\sim 360 \mathrm{~km}$. Two additional Cullinan-like Type IIa diamonds were found to have inclusions of low-Cr majoritic garnet, also indicative of a sublithospheric origin. Overall, the inclusions suggest that these diamonds originate in reduced regions of the mantle where they crystallize from Fe-Ni-C-S metallic liquids. Such regions have long been thought to exist based on experiment and theory but have never before been sampled. An estimated metal content on the order of $1 \mathrm{wt} \%$ can be calculated assuming equilibrium with pyrolitic rocks, on the basis of the average composition of the Fe-Ni-C-S inclusions and partitioning of $\mathrm{Ni}$ and $\mathrm{Fe}$ between olivine (or wadsleyite/ringwoodite) and metallic liquid.

\section{Osmium Isotope Analysis}

In order to assess the age of the metallic inclusions, their host diamonds, and further constrain the petrogenesis of the metallic phases, an Os isotopic study was initiated on one diamond from Letseng, Lesotho, containing two favorable inclusions. The metallic inclusions were accessed by cleaving polished diamond plates. The multi-phase assemblage of each partly-exposed inclusion was then characterized by qualitative EDS analysis (Figure 1). To facilitate handling of these 50-100 micron magnetic grains, Os was distilled while the metallic grains were still attached to the cleaved surface. $\mathrm{Re}$ and Os concentrations are not reported because dissolution by chromic-sulfuric preferentially attacks the pyrrhotite and its dissolution efficacy on Fe-Ni metal, cohenite and other accessory phases such as Cr-Fe-oxide is not known. Furthermore, exsolution of the homogeneous Fe-Ni-C-S liquid on exhumation will fractionate Re from Os. Aside from minor corrections for differential ingrowth of radiogenic Os since kimberlite emplacement at $90 \mathrm{Ma}$, neither of these factors will affect the Os isotopic compositions of the digested pyrrhotite. The pyrrhotite gives surprisingly low ${ }^{187} \mathrm{Os} /{ }^{188} \mathrm{Os}$ values of $0.1115 \pm 2$ and $0.1109 \pm 2$ relative to Earth's present day convecting mantle ( 0.124 to 0.132 ), which yields Neoarchean rhenium depletion model ages $\left(\mathrm{T}_{\mathrm{RD}}\right)$ of about $2.5 \mathrm{Ga}$. 
EDS Layered Image 2

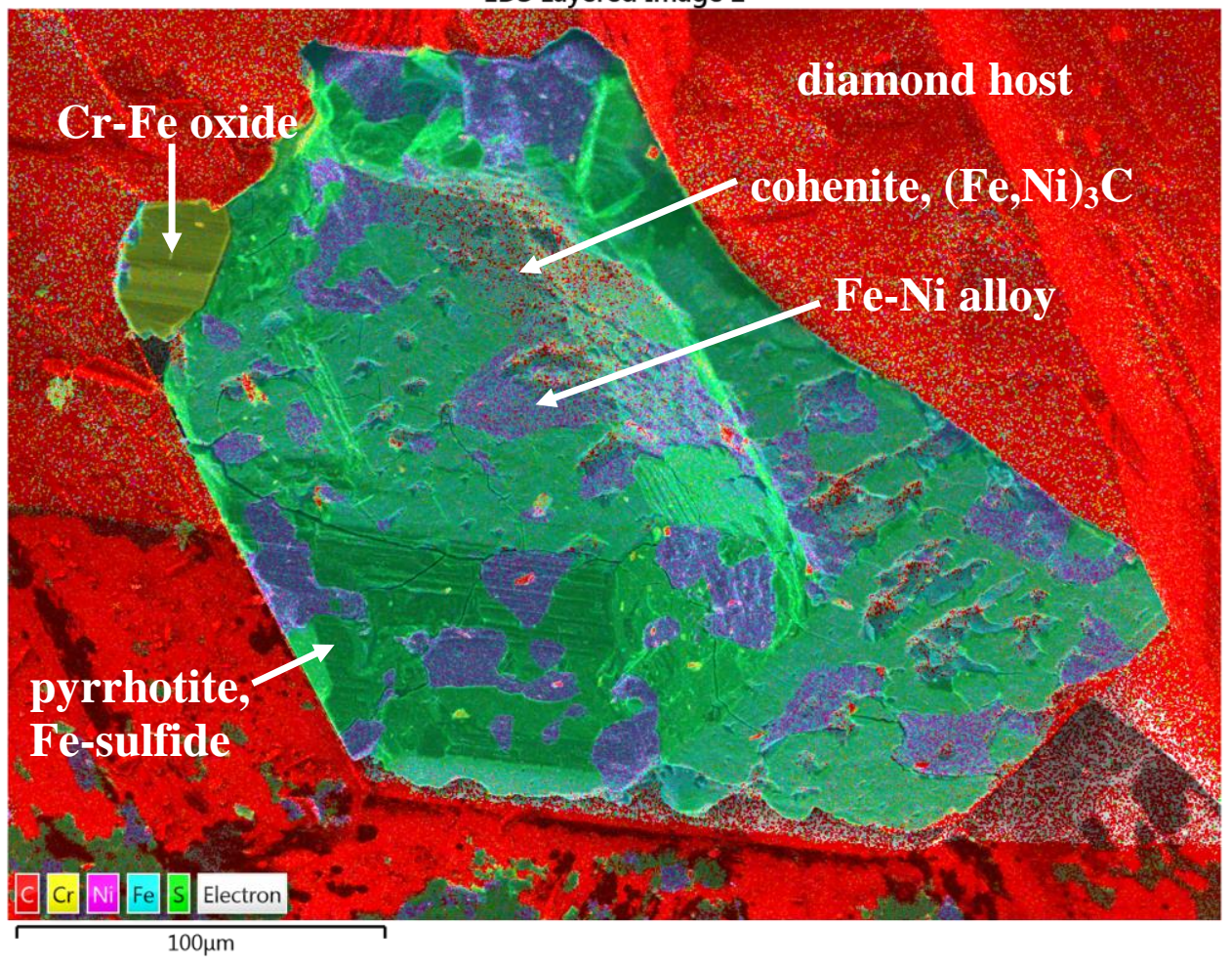

$S K \alpha 1$

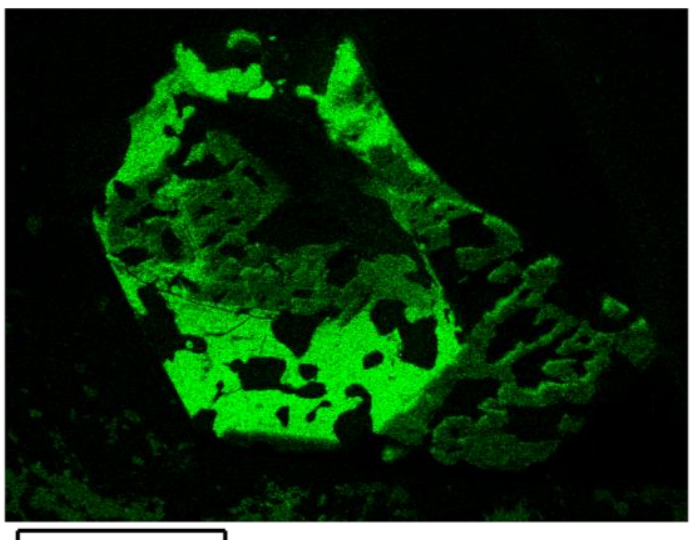

$100 \mu \mathrm{m}$

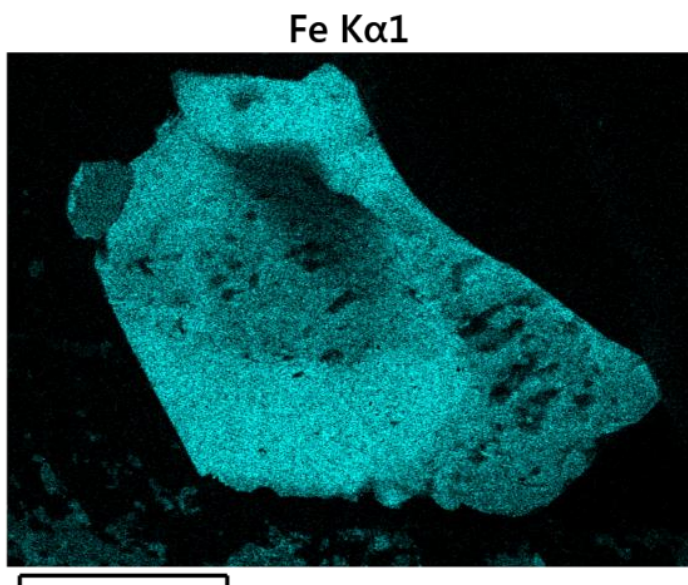

$100 \mu \mathrm{m}$
Ni K $\alpha 1$

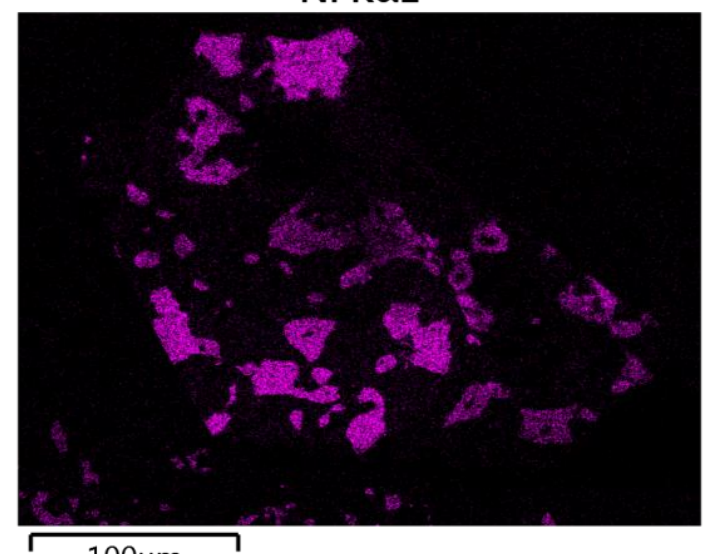

$\mathrm{Cr} \mathrm{K} \alpha 1$

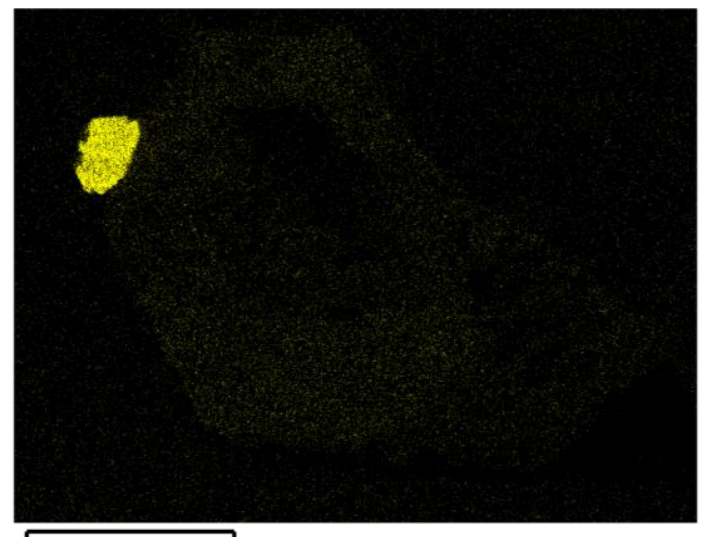

$100 \mu \mathrm{m}$

Figure 1: False color SEM X-ray element map of an exposed multi-phase Fe-Ni-C-S inclusion. 


\section{Implications}

While silicate inclusions found in these diamonds point to an eclogitic host rock (Smith et al., 2016), it appears unlikely that the metallic liquid formed originally from basaltic oceanic crust. Any basalt has a high Re/Os, making it unable to sustain such a low ${ }^{187} \mathrm{Os} /{ }^{188} \mathrm{Os}$ ratio. Furthermore, the metallic inclusions have $\mathrm{Ni} /(\mathrm{Ni}+\mathrm{Fe}$ ) ratios (Smith et al., 2016) more in line with peridotitic rocks (Zhang $\mathrm{Z}$ et al., unpublished). The old age and implicitly low time-averaged Re/Os indicated by the low ${ }^{187} \mathrm{Os} /{ }^{188}$ Os suggests that metallic liquid initially forms in peridotite, perhaps recycled together with eclogite to the mantle transition zone by Archean plate tectonics. In this scenario, migration of the metallic liquid from the peridotitic precursor to the eclogitic host could lead to further carbon (and sulfur) scavenging, supersaturation and ultimately Cullinan-like Type IIa diamond crystallization.

The metallic liquid trapped in this Letseng diamond carries a signature that is at least $2.5 \mathrm{Ga}$ old meaning that either the diamond grew at that time or it grew at a later time and incorporated an old metallic liquid. In either case, the evidence that such metallic liquids exist and that they can be old has implications for the processes by which ancient heterogeneities related to the presence of metallic liquid, such as in ${ }^{182} \mathrm{~W}$, can be preserved since soon after the formation of Earth (e.g. Mundl et al., 2017). Such metals would be expected to have an extremely high partition coefficient for W, which could preserve an ancient $\mathrm{W}$ signature against later re-equilibration.

\section{References}

Smith EM, Shirey SB, Nestola F, Bullock ES, Wang J, Richardson SH, Wang W (2016) Large gem diamonds from metallic liquid in Earth's deep mantle. Science 354: 1403-1405.

Mundl A, Touboul M, Jackson MG, Day JMD, Kurz MD, Lekic V, Helz RT, Walker RJ (2017) Tungsten-182 heterogeneity in modern ocean island basalts. Science 356: 66-69.

Zhang Z, Davis FA and Hirschmann MM (unpublished) A role for peridotite in the origin of CLIPPIR diamonds? 